\title{
Retorno ao trabalho de trabalhadores com amputação de dedos em Curitiba, PR, Brasil*
}

\section{Return to work of workers with fingers amputation in Curitiba, PR, Brazil}

\author{
Angela Paula Simonelli ${ }^{1}$ José Marçal Jackson Filho', \\ Bruna Roberta Lessa Schneider ${ }^{3}$, Débora Regina Machado ${ }^{4}$
}

http://dx.doi.org/10.11606/issn.2238-6149.v27i2p138-145

Simonelli AP, Jackson Filho JM, Schneider BRL, Machado DR. Retorno ao trabalho de trabalhadores com amputação de dedos em Curitiba, PR, Brasil. Rev Ter Ocup Univ São Paulo. 2016 maio-ago.;27(2):138-45.

RESUMO: O retorno ao trabalho de trabalhadores, vítimas de traumas de membros superiores, é determinado, não apenas por sua condição física ou biomédica, mas também por fatores psicosociais, organizacionais e ocupacionais. O objetivo deste estudo é investigar o retorno ao trabalho de um grupo de 15 sujeitos que tiveram dedos amputados em acidentes de trabalho, tratados no ambulatório de terapia ocupacional do Hospital do Trabalhador de Curitiba, PR no ano de 2012. Foi aplicado um questionário buscando informações sobre: dados sócio-demográficos, grau e mecanismo da lesão, função laboral anterior a lesão, retorno ao trabalho, função exercida após retorno e, limitações e ou dificuldades ao exercer a atividade de trabalho atual. Os resultados mostraram que dos 15 sujeitos a maioria foi re-inserida na função que exercia anteriormente, porém, muitos alegaram dificuldades na execução de suas atividades após seis meses do retorno. Isto indica a necessidade de acompanhamento no processo de retorno ao trabalho a fim de permitir a adequação das situações de trabalho aos trabalhadores re-inseridos ou estratégias para busca de outros tipos de trabalho.

DESCRITORES: Saúde do trabalhador; Terapia ocupacional; Trabalhadores; Acidente de trabalho/reabilitação; Retorno ao trabalho/ psicologia; Traumatismos dos dedos/reabilitação; Amputação traumática/psicologia; Amputação traumática/reabilitação.
Simonelli AP, Jackson Filho JM, Schneider BRL, Machado DR. Return to work of workers with fingers amputation in Curitiba, PR, Brazil, PR, Brazil. Rev Ter Ocup Univ São Paulo. 2016 May-Aug.;27(2):138-45.

ABSTRACT: Return to work in upper limb amputees is influenced not only by the physical and biomedical condition of the worker but by psychosocial factors, occupational and organizational aspects as well. The aim of this paper is to investigate the return to work of 15 patients, victims of occupational accidents with fingers trauma, after rehabilitation in the Hospital do Trabalhador in Curitiba in 2012. A questionnaire was applied searching data from: demographic information, trauma characteristics, employment status before accident and after return, and difficulties after return. It was observed that, even if the majority of the 15 workers returned to the same job, many reported difficulties in doing their activities sex months after their return to work. It reveals the need to support workers in the return to wok process aiming to adjust working conditions or to build strategies for the search of other kind of job.

KEYWORDS: Occupational health; Occupational therapy; Workers; Accidentes, occupational/rehabilitation; Return to work/psychology; Finger injuries/rehabilitation; Amputation, traumatic/psychology; Amputation, traumatic/rehabilitation.

\footnotetext{
*Este artigo apresenta resultados do projeto de pesquisa "Avaliação do retorno ao trabalho dos pacientes amputados em membro superior após tratamento de terapia ocupacional no Hospital do Trabalhador” aprovado no Comitê de Ética do Hospital do Trabalhador, parecer n 287.534. 1. Professora Adjunta. Departamento de Terapia Ocupacional, Universidade Federal do Paraná (UFPR). E-mail: angelasimonelli@ufpr.br

2. Pesquisador. Fundação Jorge Duprat Figueiredo de Segurança e Medicina do Trabalho (FUNDACENTRO). E-mail: jose.jackson@ fundacentro.gov.br

3. Terapeuta Ocupacional. Estudante de graduação na Universidade Federal do Paraná na época da pesquisa. E-mail: bru_rls@yahoo.com.br

4. Terapeuta Ocupacional. Ambulatório de Terapia Ocupacional do Hospital do Trabalhador de Curitiba, PR. E-mail: deboramachado@ sesa.pr.gov.br

Endereço para correspondência: Angela Paula Simonelli. Endereço para correspondência: Angela Paula Simonelli. Departamento de Terapia Ocupacional. Campus Botânico, Bloco Didático II. Av. Prefeito Lothário Meissner, 632. CEP: 80210-170. Jardim Botânico, Curitiba, PR, Brasil. E-mail: angelasimonelli@ufpr.br
} 


\section{INTRODUÇÃO}

$\mathrm{O}$ retorno ao trabalho de vitimados por acidentes do trabalho é, ao mesmo tempo, um grande desafio e uma necessidade premente no que tange às políticas sociais no Brasil, seja no âmbito da saúde do Trabalhador, seja no âmbito da seguridade social ${ }^{1,2}$.

$\mathrm{O}$ alto número histórico de acidentes do trabalho provoca enormes impactos negativos à sociedade, às empresas e ao Estado. Segundo análise da Previdência Social, em 2009, as despesas com reabilitação física e profissional, mais o custo indireto dos acidentes do trabalho atingiu a cifra de 42,6 bilhões de reais, além do custo com benefícios, da ordem de 14, 2 bilhões de reais ${ }^{3}$.

Mesmo assim, a insuficiência de ações e programas de reabilitação profissional, em especial, de retorno ao trabalho, constitue-se em paradoxo enfrentado cotidianamente por trabalhadores (vítimas de acidentes do trabalho) que, após período de tratamento e reabilitação funcional, devem retomar a suas atividades laborais.

Como se sabe, os acidentes do trabalho no Brasil atingem importante proporção de trabalhadores em idade produtiva (entre 20 e 49 anos), que ao se acidentarem passam a conviver com algum tipo de limitação funcional (temporária ou permanente) impactando não apenas sua vida profissional e dificultando sua reinserção ao trabalho, mas também sua vida pessoal e de sua família ${ }^{1}$.

No cenário atual, a divisão dos serviços entre instituições públicas diferentes, a assistência e a reabilitação funcional atribuídas ao SUS, e a reabilitação profissional a cargo do INSS, não contribui para o retorno ao trabalho baseado em processo de reabilitação mais abrangente $^{4}$, conforme prega a própria Constituição Federal de 1988. Segundo ela cabe ao Ministério da Previdência e Assistência Social, por meio do INSS, "proporcionar aos segurados e dependentes incapacitados (parcial ou totalmente) os meios indicados para a (re) educação e (re) adaptação profissional e social, de modo que possam voltar a participar do mercado de trabalho"s.

Com exceção de alguns programas, de determinadas instituições públicas como, por exemplo, o Centro de Orientação e Apoio Profissional da Prefeitura de São Paulo ${ }^{6}$ e o Programa de Saúde Ocupacional de Retorno ao Trabalho
(PROSORT) de um hospital de São Paulo ${ }^{7}$, implementados por serviços em algumas localidades como o Centro de Referencia em Saúde do Trabalhador (CEREST) de Piracicaba ${ }^{8}$ e por um dos centros de referência de São Paulo ${ }^{9}$ ou fundados em arranjos institucionais temporários, como o Programa de Reabilitação Ampliado de Videira, Santa Catarina ${ }^{10}$ a maior parte dos trabalhadores vitimados passa pela simples reinserção ao antigo posto, desassistido pelos serviços, em momento difícil de suas vidas profissionais. Sabe-se que a volta ao trabalho envolve sentimentos diversos e experiência difícil para os trabalhadores que terão de enfrentar antigas condições e relações de trabalho, mas em condição pessoal caracterizada por sua limitação funcional atual ${ }^{11}$.

Nesta visão reduzida, não se considera o retorno ${ }^{(1)}$ ao trabalho como um processo ${ }^{13}$, por exemplo, como propõe Young et al. ${ }^{14}$, "de desenvolvimento e dinâmico envolvendo múltiplas fases" (p.598), entre elas fases de reabilitação funcional, de reinserção no trabalho (em posto anterior ou novo posto) e de permanência.

Ao final do processo, o trabalhador pode voltar a trabalhar no mesmo posto de trabalho ou passar a exercer outras atividades ${ }^{12}$. A efetividade do processo depende de fatores individuais, físicos e organizacionais (na empresa e nos serviços) ${ }^{12}$. Para melhor readaptação do trabalhador, é necessário o acompanhamento do sujeito, no qual suas atividades e condições de trabalho devem ser analisadas a fim de que sejam propostas adaptações e se garanta a sua permanência ${ }^{8}$.

A produção de conhecimento sobre o retorno ao trabalho das vítimas de acidente do trabalho e o debate sobre este tema são fundamentais para aprimorar programas já existentes e desenhar novas propostas mais efetivas quanto a reinserção de trabalhadores ${ }^{13}$.

No caso de acidentes que envolvem membros superiores dos trabalhadores, sabe-se qua a prevalência é bastante elevada, que dedos e mãos são, respectivamente, as partes do corpo mais atingidas, sobretudo de trabalhadores em idade produtiva ${ }^{15,16}$. De qualquer modo, como afirmam Cabral e colaboradoras, no caso destes traumas, qualquer lesão, independentemente de sua gravidade, pode provocar grau de incapacidade tanto para as atividades de trabalho e de vida, mas com maior impacto para a primeira ${ }^{15}$. O retorno ao trabalho de trabalhadores, vitima de traumas de membros superiores, é determinado, não apenas por

(1) Para Schultz et al. ${ }^{12}$, após exaustiva revisão sistemática sobre o tema, não há definição clara para a expressão 'retorno ao trabalho'. Segundo estes autores, 'o termo 'retorno ao trabalho' é utilizado tanto como um processo quanto medida de desfecho. RT pode ser concebido como o 'processo' de retorno' de trabalhador acometido de lesão para o trabalho (por exemplo, retorno gradativo ao trabalho ou acomodação na função), ou ser o desfecho final mensurável da incapacidade: o status de trabalhar ou não trabalhar' (p.329-30). 
sua condição física ou biomédica, mas também por fatores psicosociais, organizacionais e ocupacionais ${ }^{13,17}$.

Neste estudo, a compreensão sobre funcionalidade e incapacidade de uma pessoa são concebidas como uma interação dinâmica entre os estados de saúde (doenças, perturbações, lesões etc.) e os fatores contextuais (fatores ambientais e pessoais) como abordado pela Classificação Internacional de Funcionalidade, Incapacidade e Saúde - CIF. A incapacidade não é um atributo da pessoa, mas sim um conjunto complexo de condições que resulta da interação pessoa-meio ${ }^{18}$.

O Departamento de Terapia Ocupacional (DTO) da Universidade Federal do Paraná (UFPR) oferece, por meio de convênio, estágio curricular no ambulatório de terapia ocupacional do Hospital do Trabalhador (HT), que realiza reabilitação funcional de indivíduos que sofreram trauma e lesionaram membros superiores. A cooperação entre as duas instituições não se resume à formação de terapeutas ocupacionais, mas também visa a produção de conhecimentos sobre os usuários do serviço, práticas do serviço e sua efetividade. Recentemente, um estudo para caracterizar a população atendida neste ambulatório foi realizado.

A análise dos prontuários referentes aos atendimentos realizados no período de janeiro de 2010 a março de 2012, no ambulatório de terapia ocupacional do Hospital do Trabalhador (HT) de Curitiba, PR, totalizando 1.723 prontuários, apresentou que dentre o total de prontuários, 497 configuraram lesões por acidentes de trabalho, o que representou $28,8 \%$ do total de atendimentos. Alta incidência de casos de amputação também foi observada ${ }^{19}$.

A ocorrência de acidentes de trabalho predomina entre trabalhadores do gênero masculino, que representou $86,72 \%$ dos atendimentos. Os setores de trabalho que se destacaram com altos índices de ocorrência de acidentes de trabalho foram: construção civil, metalurgia, serviços gerais, transportes e correios e alimentação e os postos de trabalho que apresentaram maiores índices de acidentes foram: auxiliar de produção e operador de máquina ${ }^{19}$.

Como forma de continuidade da exploração deste tema, o objetivo do presente estudo é investigar o retorno ao trabalho de um grupo de sujeitos que tiveram dedos amputados em acidentes de trabalho típicos e que realizaram tratamento de reabilitação funcional no ambulatório de terapia ocupacional do Hospital do Trabalhador de Curitiba, PR no ano de 2013.

\section{PROCEDIMENTOS METODOLÓGICOS}

Estudo descritivo foi realizado por meio da parceria entre o Departamento de Terapia Ocupacional da UFPR e o Ambulatório de Terapia Ocupacional do Hospital do Trabalhador. Os dados foram coletados no período de 10 de junho a 07 de novembro de 2013.

Foram analisados os prontuários dos sujeitos atendidos entre 01 de janeiro de 2012 a 23 de dezembro de 2012, que realizaram tratamento e que receberam alta após este período, a fim de, selecionar aqueles que sofreram algum tipo de amputação de dedos decorrente de acidente de trabalho e que retornaram ao trabalho há pelo menos seis meses. Duzentos e dez trabalhadores foram considerados elegíveis aos critérios acima citados.

No entanto, estes trabalhadores, após pesquisa de prontuários, já haviam recebido alta de seu tratamento e retornado às suas atividades de trabalho, dificultando portanto, o contato dos pesquisadores. Desta forma, a amostra final foi composta por apenas 15 trabalhadores, pois na maioria dos casos o número telefônico disponível no serviço não estava mais habilitado, outros não puderam se ausentar do trabalho para responder a pesquisa, alguns não aceitaram participar, dentre outros motivos.

Realizou-se o agendamento via telefone dos 15 sujeitos que compareceram no HT para a aplicação de questionário.

Para a coleta de dados, foi aplicado um questionário composto por perguntas semi-estruturadas, compreendendo: dados sócio-demográficos (gênero e faixa etária); grau e mecanismo da lesão (tipo de acidente e tipo de lesão); função laboral anterior a lesão; tempo de afastamento do trabalho, se retornou ao trabalho; função exercida após retorno e limitações e ou dificuldades ao exercer a atividade de trabalho atual devido à limitações do uso da mão. Buscou-se verificar se o sujeito esta trabalhando em sua antiga atividade de trabalho, se ele está atuando em outras atividades e quais as dificuldades de movimentação biomecânica da mão que o sujeito apresenta após o retorno ao trabalho.

O estudo foi aprovado pelo Comitê de Ética do Hospital do Trabalhador, sob o $\mathrm{n}^{\circ}$ do parecer 287.534. Todos os sujeitos que concordaram em participar da pesquisa assinaram o Termo de Consentimento Livre e Esclarecido.

\section{RESULTADOS}

A amostra do estudo caracterizou-se por 15 sujeitos que sofreram amputações devido à acidentes típicos de trabalho. Houve predominância de sujeitos do sexo masculino (12 sujeitos do total da amostra), e outros três eram do sexo feminino (Quadro 1).

Os sujeitos apresentaram entre 26 e 67 anos. A faixa etária predominante concentrou-se entre 26 e 46 anos de idade, ou seja, faixa economicamente ativa da população (Quadro 1). 
Quadro 1 - Dados socio-demagráficos, grau e mecanismo da lesão, afastamento e retorno ao trabalho e limitações do uso da mão pela população do estudo

\begin{tabular}{|c|c|c|c|c|c|c|c|c|}
\hline Caso & Lesão (grau) & Gênero & $\begin{array}{l}\text { Faixa } \\
\text { etária }\end{array}$ & $\begin{array}{l}\text { Função } \\
\text { exercida no } \\
\text { trabalho }\end{array}$ & $\begin{array}{l}\text { Mecanismo } \\
\text { de lesão } \\
\text { (acedente) }\end{array}$ & $\begin{array}{l}\text { Tempo de } \\
\text { afastamento } \\
\text { (desde o } \\
\text { acidente até } \\
\text { o retorno ao } \\
\text { trabalho) }\end{array}$ & $\begin{array}{l}\text { Função } \\
\text { realizada no } \\
\text { retorno ao } \\
\text { trabalho }\end{array}$ & $\begin{array}{l}\text { Dificuldades para } \\
\text { exercer a função } \\
\text { atual }\end{array}$ \\
\hline 1 & $\begin{array}{l}\text { Polpa digital do } 1^{\circ} \\
\text { dedo }\end{array}$ & Fem & 50 & $\begin{array}{l}\text { Auxiliar de } \\
\text { produção }\end{array}$ & $\begin{array}{l}\text { Esmagamento } \\
\text { por Prensa }\end{array}$ & 15 dias & $\begin{array}{l}\text { Mesma } \\
\text { função }\end{array}$ & Não informou \\
\hline 2 & $\begin{array}{l}\text { Falange média } 5^{\circ} \\
\text { dedo }\end{array}$ & Masc & 31 & $\begin{array}{l}\text { Encarregado } \\
\text { de } \\
\text { manutenção } \\
\end{array}$ & Serra circular & 1 mês & $\begin{array}{l}\text { Mesma } \\
\text { função }\end{array}$ & $\begin{array}{l}\text { Carregar e manusear } \\
\text { objetos pesados }\end{array}$ \\
\hline 3 & $\begin{array}{l}3^{\circ} \text { e } 4^{\circ} \text { dedos (nível } \\
\text { falange distal) }\end{array}$ & Masc & 26 & Pedreiro & $\begin{array}{l}\text { Esmagamento } \\
\text { por } \\
\text { retroescavadeira }\end{array}$ & 6 meses & $\begin{array}{l}\text { Mesma } \\
\text { função }\end{array}$ & Sem limitações \\
\hline 4 & $\begin{array}{l}1^{\circ} \text { dedo (nível } \\
\text { falange proximal) }\end{array}$ & Masc & 31 & $\begin{array}{l}\text { Auxiliar de } \\
\text { produção }\end{array}$ & $\begin{array}{l}\text { Esmagamento } \\
\text { por Prensa }\end{array}$ & 4 meses & $\begin{array}{l}\text { Mesma } \\
\text { função }\end{array}$ & $\begin{array}{l}\text { Pegar e encaixar } \\
\text { objetos pequenos }\end{array}$ \\
\hline 5 & $\begin{array}{l}1^{\circ} \text { dedo } \\
\text { (amputação } \\
\text { completa) }\end{array}$ & Masc & 46 & Metalúrgico & $\begin{array}{l}\text { Esmagamento } \\
\text { por Prensa }\end{array}$ & 3 meses & $\begin{array}{l}\text { Mesma } \\
\text { função }\end{array}$ & $\begin{array}{l}\text { Segurar e manusear } \\
\text { objetos pequenos; } \\
\text { Carregar objetos } \\
\text { pesados }\end{array}$ \\
\hline 6 & $\begin{array}{l}2^{\circ} \text { e } 3^{\circ} \text { dedos (nível } \\
\text { falange média) e } 4^{\circ} \\
\text { dedo (nível polpa } \\
\text { digital) }\end{array}$ & Masc & 32 & $\begin{array}{l}\text { Auxiliar de } \\
\text { produção }\end{array}$ & Serra circular & 9 meses & $\begin{array}{l}\text { Mudança } \\
\text { de função } \\
\text { (solicitação } \\
\text { própria) }\end{array}$ & $\begin{array}{l}\text { Carregar objetos } \\
\text { pesados e manipular } \\
\text { objetos pequenos }\end{array}$ \\
\hline 7 & $\begin{array}{l}2^{\circ} \text { dedo } \\
\text { (amputação } \\
\text { completa) }\end{array}$ & Masc & 26 & $\begin{array}{l}\text { Auxiliar de } \\
\text { produção }\end{array}$ & Serra circular & 1 ano & $\begin{array}{l}\text { Mesma } \\
\text { função }\end{array}$ & $\begin{array}{l}\text { Pegar objetos } \\
\text { pequenos; encaixar } \\
\text { peças pequenas }\end{array}$ \\
\hline 8 & $\begin{array}{l}2^{\circ} 3^{\circ} \text { dedos (nível } \\
\text { falange distal) }\end{array}$ & Masc & 33 & $\begin{array}{l}\text { Auxiliar de } \\
\text { produção }\end{array}$ & $\begin{array}{l}\text { Esmagamento } \\
\text { por Prensa }\end{array}$ & 4 meses & $\begin{array}{l}\text { Mesma } \\
\text { função }\end{array}$ & Sem limitações \\
\hline 9 & $\begin{array}{l}2^{\circ} \text { dedo (nível } \\
\text { interfalangeana } \\
\text { distal) }\end{array}$ & Masc & 36 & $\begin{array}{l}\text { Encarregado } \\
\text { de estoque }\end{array}$ & $\begin{array}{l}\text { Maquina de } \\
\text { borracha }\end{array}$ & 1 mês & $\begin{array}{l}\text { Mesma } \\
\text { função }\end{array}$ & Sem limitações \\
\hline 10 & $\begin{array}{l}5^{\circ} \text { dedo (nível } \\
\text { falange distal) }\end{array}$ & Fem & 44 & $\begin{array}{l}\text { Vendedora } \\
\text { autonoma }\end{array}$ & $\begin{array}{l}\text { Bomba } \\
\text { pneumática }\end{array}$ & 3 meses & $\begin{array}{l}\text { Mesma } \\
\text { função }\end{array}$ & Não informou \\
\hline 11 & $\begin{array}{l}3^{\circ} \text { dedo (polpa } \\
\text { digital) }\end{array}$ & Masc & 56 & $\begin{array}{l}\text { Pintor de } \\
\text { obras }\end{array}$ & $\begin{array}{l}\text { Esmagamento } \\
\text { por correia }\end{array}$ & 3,5 meses & $\begin{array}{l}\text { Mesma } \\
\text { função }\end{array}$ & Sem limitações \\
\hline 12 & $\begin{array}{l}2^{\circ} \text { dedo (nível } \\
\text { interfalangeana } \\
\text { distal) }\end{array}$ & Masc & 26 & $\begin{array}{l}\text { Operador de } \\
\text { maquina }\end{array}$ & Serra circular & 4 meses & $\begin{array}{l}\text { Mesma } \\
\text { função }\end{array}$ & Sem limitações \\
\hline 13 & $\begin{array}{l}2^{\circ} \text { dedo (nível } \\
\text { interfalangeana } \\
\text { distal) }\end{array}$ & Masc & 57 & Soldador & $\begin{array}{l}\text { Esmagamento } \\
\text { por eixo de } \\
\text { onibus }\end{array}$ & 6 meses & $\begin{array}{l}\text { Mesma } \\
\text { função }\end{array}$ & Sem limitações \\
\hline 14 & $\begin{array}{l}1^{\circ} \text { dedo } \\
\text { (amputação } \\
\text { completa) }\end{array}$ & Masc & 60 & Eletricista & $\begin{array}{l}\text { Bomba } \\
\text { pneumática }\end{array}$ & 1 ano & $\begin{array}{l}\text { Mesma } \\
\text { função }\end{array}$ & $\begin{array}{l}\text { Segurar e manusear } \\
\text { fios, parafusos }\end{array}$ \\
\hline 15 & $\begin{array}{l}2^{\circ} \text { dedo (nível } \\
\text { interfalangeana } \\
\text { distal) }\end{array}$ & Fem & 67 & $\begin{array}{l}\text { Coletor de } \\
\text { lixo }\end{array}$ & $\begin{array}{l}\text { Esmagamento } \\
\text { por container }\end{array}$ & 4 meses & $\begin{array}{l}\text { Mesma } \\
\text { função }\end{array}$ & $\begin{array}{l}\text { Carregar objetos } \\
\text { pesados }\end{array}$ \\
\hline
\end{tabular}


Após a lesão, o tempo de afastamento para reabilitação clínica-funcional foi variável, principalmente em decorrência da gravidade e do grau da lesão. Em um caso, o sujeito permaneceu apenas 15 dias afastado em reabilitação clínica-funcional e, em outros dois casos, este processo durou um ano (Quadro 1).

Neste estudo, a totalidade dos traumas ocorreram por acidentes de trabalho típico, na maior parte dos casos o mecanismo de lesão foi corte por serra circular e esmagamento por prensa (4 casos em cada evento). Quanto aos demais, observaram-se esmagamento por retroescavadeira, esmagamento por cantâiner, esmagamento por eixo de ônibus, esmagamento por correia, bomba pneumática e máquina de borracha (Quadro 1).

As ocupações exercidas pelos sujeitos antes dos acidentes eram: auxiliar de produção, encarregado de manutenção, pedreiro, metalúrgico, encarregado de estoque, vendedor (autônomo), pintor, operador de máquina, soldador, eletricista e coletor de lixo (Quadro 1).

Quanto ao retorno ao trabalho, 14 sujeitos retornaram ao trabalho e a realizar a mesma função exercida anteriormente ao acidente (Quadro 1). Vale ressaltar que as entrevistas foram realizadas pelo menos após seis meses que os sujeitos haviam retornado ao trabalho.

Dentre o total da amostra, um sujeito teve sua atividade de trabalho modificada, por solicitação própria, pois, temia que sua atividade anterior à lesão fosse lhe causar prejuízos à saúde em sua situação atual. Este sujeito possui 32 anos, sexo masculino, é auxiliar de produção e se acidentou utilizando serra circular. Teve o $2^{\circ}$ e $3^{\circ}$ dedos (nível falange média) e $4^{\circ}$ dedo (nível polpa digital) amputados. Ficou nove meses afastado em reabilitação funcional.

Em relação às limitações para a realização das atividades de trabalho, dentre o total da amostra, seis relataram não possuir qualquer limitação decorrente da ausência parcial da estrutura da mão para execução das tarefas de trabalho. Vale ressaltar que todos os seis que não relataram limitações voltaram a realizar a mesma atividade que realizavam antes do acidente. Outros sete sujeitos relataram dificuldades para realizar atividades como: carregar e manusear objetos pesados, pegar e encaixar objetos pequenos, segurar e manusear objetos pequenos, segurar e manusear fios e parafusos. Destes, seis retornaram ao trabalho nas mesmas atividades que exerciam antes do acidente e um teve mudança no conteúdo de suas tarefas por solicitação própria. Segundo relato, essas dificuldades foram amenizadas quando suas tarefas foram adequadas às suas habilidades e limitações pós-acidente. Apenas dois sujeitos não informaram sobre suas limitações e/ou dificuldades na realização das atividades de trabalho (Quadro 1).

\section{DISCUSSÃO}

Neste estudo, os 15 sujeitos que foram entrevistados, retornaram ao trabalho após tratamento, corroborando a tendência que se observa na literatura tanto em estudos nacionais quanto internacionais, na qual trabalhadores com amputação de membro superior apresentam alto índice de retorno ao trabalho após reabilitação. Em estudo realizado serviço de reabilitação profissional do Hospital Maria Amélia Lins em Belo Horizonte, 30 de 35 trabalhadores retornaram ao trabalho ${ }^{15}$; já no estudo clássico de Millstein et al. ${ }^{20}$, que contou com 1010 sujeitos, 89\% deles retornaram ao trabalho, mas, se considerados amputados de membros superiores a taxa foi de $93 \%$.

Importante destacar que o baixo número de participantes deste estudo, 15 sujeitos, não permite assegurar sua validade para a totalidade dos trabalhadores, 210, com amputação registrados no serviço. Como descrito nos procedimentos metodológicos isso se explica devido a dificuldade de contactar os trabalhadores e agendar a aplicação dos questionários.

Apesar do alto índice de retorno, que pode estar associada a idade dos sujeitos (jovens), ao tipo e baixa severidade das lesões, verificou-se baixo índice de mudanças na área de atuação, bem como, da composição das tarefas de trabalho. Apenas, um sujeito da amostra teve sua atividade modificada, sendo alocado em outra função, o que pode ser explicado pela política da empresa na valorização da auto-avaliação do trabalhador sobre sua capacidade laborativa.

Além da existência de políticas ou programas internos às empresas, sabe-se que a reinserção em outros postos de trabalho ou outros empregos é possível quando os sujeitos possuem maior nível de escolaridade, permitindo-se evitar atividades com alta carga de trabalho, mas de maiores exigências intelectuais ${ }^{15,20}$. Na pesquisa de Millstein et al. ${ }^{20}$, dos $89 \%$ de trabalhadores que retornaram ao trabalho, 75\% foram inseridos em postos distintos de sua área de atuação.

Neste estudo, mais da metade dos sujeitos relatou alguma dificuldade específica na realização de suas atividades de trabalho. Destes, a maioria retornou às mesmas atividades de trabalho apesar de suas queixas quanto às limitações para, por exemplo, carregar e 
manusear objetos pesados, pegar e encaixar objetos pequenos, segurar e manusear objetos pequenos, segurar e manusear fios e parafusos, dentre outras, o que se confirma, por exemplo, no caso do estudo realizado no Hospital Maria Amélia Lins em Belo Horizonte ${ }^{15}$. Vale ressaltar que este estudo não investigou o grau de dificuldade apresentada pelos trabalhadores e que houve variações no tempo de retorno ao trabalho, porém, todos os sujeitos já haviam retornado às suas atividades há pelo menos 6 meses no momento da entrevista.

Por um lado, o retorno ao trabalho é uma fase da vida difícil para os sujeitos, caracterizada por muitas incertezas quanto ao futuro e insegurança quanto a sua recuperação e capacidade laboral, diante das novas limitações ${ }^{11}$; por outro, sabe-se que aspectos psicossociais, como os relatados acima, se não forem superados ou abordados podem se constituir em impeditivos ao retorno ${ }^{17}$.

Além disso, o retorno também depende de fatores relacionados ao trabalho, às condições físicas dos postos, às relações com colegas e hierarquia e às exigências organizacionais ${ }^{8,13,15,17,21,22}$, à postura da empresa ou do mercado de trabalho ${ }^{23}$.

Por isso, o acompanhamento dos trabalhadores durante a reabilitação clinica-funcional de qualidade e eficiente seguida do retorno ao trabalho, assegurando o suporte emocional necessário, e a possibilidade da análise da atividade no posto escolhido para melhor adaptação do trabalhador, é condição para permanência no longo prazo no trabalho ${ }^{15}$.

No estudo em tela, verificou-se, todavia, que após o período de tratamento na reabilitação clínicafuncional do ambulatório de terapia ocupacional, os sujeitos não tiveram nenhum tipo de acompanhamento para retornarem ao trabalho. O serviço de Reabilitação Clínica-Funcional citado neste estudo tem como principal função a reabilitação ortopédica-funcional. Trabalha com conceitos que considera fatores contextuais do trabalho e o empoderamento dos sujeitos, porém, se limita ao espaço do hospital. Não são realizados estudos da atividade de trabalho no local de trabalho, bem como, acompanhamento do sujeito após tratamento para verificação de possíveis adaptações para a realização das atividades.

Apesar das limitações apontadas, o estudo mostra a necessidade da continuidade de atividades a serem realizadas pelo Laboratório de Reabilitação, Acessibilidade e Trabalho - LABRAT/DTO em parceira com o ambulatório de terapia ocupacional do HT-Curitiba, a fim de melhor compreender, por meio de projetos de pesquisa e de extensão, a situação dos trabalhadores acidentados e sua relação com a reintegração no trabalho.

A cooperação entre universidade e serviços é uma premissa do SUS $^{24}$ que permite o enfrentamento de questão social tão relevante para os trabalhadores, como é o caso do retorno ao trabalho após tratamento de trauma. A partir desta atuação conjunta, modelos mais completos e integrais de atenção às vítimas do trabalho podem ser construídos e implementados, no campo da reabilitação profissional ${ }^{8,9,10,13,15}$. Trata-se de questão essencial para aqueles que pensam e praticam a Terapia Ocupacional em suas relações com a Saúde do Trabalhador ${ }^{25}$.

\section{CONCLUSÃO}

Os resultados mostram que houve alto índice de retorno ao trabalho do grupo de reabilitação clinicafuncional considerado na pesquisa. A maioria foi re-inserida na função anterior, mas muitos alegaram dificuldades na execução de suas atividades após pelo menos seis meses do retorno às atividades de trabalho.

Isto indica a necessidade de acompanhamento no processo de retorno ao trabalho, o que poderia permitir a adequação das situações de trabalho aos trabalhadores reinseridos ou estratégias para busca de outros tipos de atividades, com menor exigência física, por exemplo.

Abre-se, desta forma, campo de investigação futura que passa pela compreensão do processo de adoecimentodeficiência-funcionalidade-retorno ao trabalho no longo prazo, baseado em novo arranjo institucional incluindo outros atores do setor saúde, do trabalho e eventualmente da previdência.

Contribuições dos autores: Angela Paula Simonelli. Responsável por todos os aspectos do trabalho na garantia da exatidão e integridade de qualquer parte da obra e aprovação final da versão a ser publicada; José Marçal Jackson Filho. Redação do artigo e revisão crítica relevante do conteúdo intelectual e aprovação final da versão a ser publicada; Bruna Roberta Lessa Schneider: Coleta, análise, interpretação dos dados e aprovação final da versão a ser publicada; Débora Regina Machado: Coleta de dados e aprovação final da versão a ser publicada. 


\section{REFERÊNCIAS}

1. Takahashi M, Kato M, Leite RAO. Incapacidade, reabilitação profissional e saúde do trabalhador: velhas questões, novas abordagens. Rev Bras Saúde Ocup. 2010;35(121):7-9. DOI: http://dx.doi.org/10.1590/S0303-76572010000100002.

2. Maeno M, Vilela RAG. Reabilitação profissional no Brasil: elementos para a construção de uma política pública. Rev Bras Saúde Ocup. 2010;35(121):87-99. DOI: http://dx.doi. org/10.1590/S0303-76572010000100010.

3. Melo LEA. A Previdência Social e a luta contra os acidentes e doenças do trabalho no Brasil. Inf Previdência Social. 2011 jun.;23(7). Disponível em: http://www.previdencia.gov.br/ arquivos/office/3_110728-104424-440.pdf.

4. Maeno M, Takahashi MAC, Lima MAG. Reabilitação profissional como política de inclusão social. Acta Fisiatr. 2009;16(2):53-8. Disponível em: http:/www.actafisiatrica. org.br/detalhe_artigo.asp?id=108\#.

5. Brasil. Ministério da Previdência e Assistência Social (MPAS). Sobre a Previdência Social. Brasília; 2003. Disponivel em: http://www.previdenciasocial.gov. Br.

6. Carneiro SAM. Saúde do trabalhador público: questão para a gestão de pessoas - a experiência na Prefeitura de São Paulo. Rev Serviço Público. 2006;57(1):23-49. Disponível em: http://seer.enap.gov.br/index.php/RSP/article/view/188.

7. Vieira GS, Glina DMR, Pustiglione M, Rocha, LE, CostaBlack KM. Programa de retorno ao trabalho em um hospital de São Paulo: resultados iniciais, fatores facilitadores e obstáculos de uma perspectiva administrativa. Rev Bras Med Trab. 2010;8(2):105-14. Disponível em: http://www.anamt. org.br/site/upload_arquivos/revista_brasileira_volume_8 no_2_-_dez_2010_12122013101735795186.pdf.

8. Takahashi, MABC, Simonelli, AP, Sousa HP, Mendes RWB, Alvarenga MVA. Programa de reabilitação profissional para trabalhadores com incapacidades por LER/DORT: relato de experiência do Cerest-Piracicaba, SP. Rev Bras Saúde Ocup. 2010;35(121):100-11. DOI: http://dx.doi.org/10.1590/ S0303-76572010000100011.

9. Toldrá RC, Daldon MTB, Santos MC, Lancman S. Facilitadores e barreiras para o retorno ao trabalho: a experiência de trabalhadores atendidos em um centro de referência em saúde do trabalhador - SP, Brasil. Rev Bras Saúde Ocup. 2010;35(121):10-22. DOI: http://dx.doi. org/10.1590/S0303-76572010000100003.

10. Bartilotti CB, Andrade PR, Varandas JM, Ferreira PCG, Cabral C. Programa de Reabilitação Ampliada (PRA): uma abordagem multidimensional do processo de reabilitação profissional. Acta Fisiatr 2009;16(2):66-75. DOI: http:// dx.doi.org/10.1590/S0104-12902013000300008
11. Souza MEL, Faiman CJS. Trabalho, saúde e identidade: repercussões do retorno ao trabalho, após afastamento por doença ou acidente, na identidade profissional. Saúde Ética Justiça. 2007;12(1/2):22-32. DOI: http://dx.doi.org/10.11606/ issn.2317-2770.v12i1-2p22-32.

12. Schultz, IZ, Stowell, AW, Feneurstein, M, Gatchel RJ. Models of return to work for musculoskeletal disorders. J Occup Rehabil. 2007;17(2):327-52. DOI: 10.1007/s10926007-9071-6.

13. Saldanha JHS, Pereira APM, Neves RF, Lima MAG. Facilitadores e barreiras de retorno ao trabalho de trabalhadores acometidos por LER/DORT. Rev Bras Saúde Ocup. 2013;38(127):122-38. DOI: http://dx.doi.org/10.1590/ S0303-76572013000100014.

14. Young AE, Roessler RT, Wasiak R, McPherson, KM, Poppel, MNM, Anema, JR. A developmental conceptualization of return to work. J Occup Rehabil. 2005;15(4):557-68. DOI: 10.1007/s10926-005-8034-z.

15. Cabral LHA, Sampaio RF, Figueiredo IM, Mancini MC. Fatores associados ao retorno ao trabalho após um trauma de mão: uma abordagem qualiquantitativa. Rev Bras Fisioter. 2010;14(2):149-57. Disponível em: http://dx.doi. org/10.1590/S1413-35552010005000004.

16. Souza MAP, Cabral LHA, Sampaio RF, Mancini MC. Acidentes de trabalho envolvendo mãos: casos atendidos em um serviço de reabilitação. Fisioter Pesqui. 2008;15(1):64-71. DOI: http://dx.doi.org/10.1590/S1809-29502008000100011.

17. Opsteegh L, Reinders-Messelink HA, Schollier D, Groothoff JW, Postema K, Dijkstra PU, Van der Sluis CK. Determinants of return to work in patients with hand disorders and hand injuries. J Occup Rehabil. 2009;19:245-55. DOI: 10.1007/ s10926-009-9181-4.

18. Buchalla CM, organizador. Classificação Internacional de Funcionalidade, Incapacidade e Saúde - CIF - 2003. São Paulo: Editora da Universidade de São Paulo; 2003.

19. Balsano M, Simonelli AP. Caracterização dos tipos de acidentes de trabalho do Ambulatório de Terapia Ocupacional do Hospital do Trabalhador de Curitiba, PR. Cad Ter Ocup UFSCar (São Carlos). 2015;23(1):53-61. DOI: 10.4322/0104-4931.ctoAO443.

20. Millstein S, Bain D, Hunter GA. A review of employment patterns of industrial amputees- -factors influencing rehabilitation. Prosthet Orthot Int. 1985;9(2):69-78. DOI: $10.3109 / 03093648509164708$.

21. Gravina MER, Rocha LE. Lesões por esforços repetitivos em bancários: reflexões sobre o retorno ao trabalho. Cad Psicol Soc Trab. 2006;9(2):41-55. DOI: 10.11606/issn.1981-0490. v9i2p41-55. 
22. MacaiaAAS, Fischer FM. Retorno ao trabalho de professores após afastamentos por transtornos mentais. Saúde Soc. 2015;24:84152. DOI: http://dx.doi.org/10.1590/S0104-12902015130569.

23. Fernández A, Isusi I, Gómez M. Factors conditioning the return to work of upper limb aputees in Asturias, Spain. Prosthet Orthot Int. 2000;24:1434-47. DOI: $10.1080 / 03093640008726537$
24. Vilela RAG. Vigilância em saúde do trabalhador e produção acadêmica: uma articulação dispensável. Cien Saude Coletiva. 2011;16(8):3369-72. DOI: http://dx.doi. org/10.1590/S1413-81232011000900003.

25. Simonelli AP, Rodrigues DS. Saúde e trabalho em debate: velhas questões, novas perspectivas. Brasília (DF): Paralelo $15 ; 2013$.

Recebido em: 03.10.15

Aceito em: 18.04.16 